\title{
BMJ Open Impact of social service and public health spending on teenage birth rates across the USA: an ecological study
}

\author{
Heather L Sipsma, ${ }^{1,2}$ Maureen Canavan, ${ }^{1}$ Melissa Gilliam, ${ }^{2}$ Elizabeth Bradley ${ }^{1}$
}

To cite: Sipsma HL, Canavan M, Gilliam M, et al. Impact of social service and public health spending on teenage birth rates across the USA: an ecological study. BMJ Open 2017;7:e013601. doi:10.1136/ bmjopen-2016-013601

- Prepublication history for this paper is available online. To view these files please visit the journal online (http://dx.doi. org/10.1136/bmjopen-2016013601).

Received 27 July 2016 Revised 7 April 2017 Accepted 10 April 2017

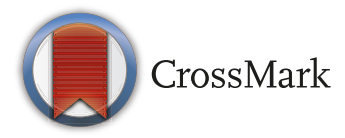

1'Department of Health Policy and Management, Yale School of Public Health, New Haven, Connecticut, USA

${ }^{2}$ Center for Interdisciplinary Inquiry and Innovation in Sexual and Reproductive Health, University of Chicago, Chicago, Illinois, USA

Correspondence to

Dr Heather L Sipsma; hsipsma@ ben.edu

\section{ABSTRACT}

Objective To examine whether greater state-level spending on social and public health services such as income, education and public safety is associated with lower rates of teenage births in USA.

Design Ecological study.

Setting USA.

Participants 50 states.

Primary outcome measure Our primary outcome measure was teenage birth rates. For analyses, we constructed marginal models using repeated measures to test the effect of social spending on teenage birth rates, accounting for several potential confounders.

Results The unadjusted and adjusted models across all years demonstrated significant effects of spending and suggested that higher spending rates were associated with lower rates of teenage birth, with effects slightly diminishing with each increase in spending (linear effect: $\mathrm{B}=-0.20 ; 95 \% \mathrm{Cl}-0.31$ to $0.08 ; \mathrm{p}<0.001$ and quadratic effect: $\mathrm{B}=0.003 ; 95 \% \mathrm{Cl} 0.002$ to $0.005 ; \mathrm{p}<0.001$ ).

Conclusion Higher state spending on social and public health services is associated with lower rates of teenage births. As states seek ways to limit healthcare costs associated with teenage birth rates, our findings suggest that protecting existing social service investments will be critical.

\section{INTRODUCTION}

Despite substantial declines over the last two decades, USA continues to have the highest teenage birth rate of any industrialised country. ${ }^{1}$ Annually, more than 270000 babies are born to young women between 15 and 19 years of age, ${ }^{2}$ and rates vary widely across states from 13 births to 48 births per 1000 women ages $15-19$. Teenage births have a tremendous effect on the lives of parents and children. Teenage mothers and fathers tend to have more limited educational attainment and economic opportunities and less marital stability than their peers who delay childbearing. ${ }^{3}$ Teenage parenthood, thus, tends to preserve disadvantaged contexts and perpetuates intergenerational cycles of young childbearing. ${ }^{45}$

Previous studies have found that contextual factors-such as poverty, ${ }^{6}$ income inequality, ${ }^{7}$
Strengths and limitations of this study

- Previous research has not explored the association between state-level spending on social and public health services and teenage birth rates.

- Despite the use of lagged effects, our analysis cannot establish temporality with these data.

- Although our state-level analysis should not be used to make inferences about relationships at an individual level, our findings may inform statelevel spending choices for policy makers and practitioners.

- We were unable to detect which services were most strongly associated with teenage birth rates, as spending on different services was highly correlated in these observational data.

unemployment $^{8}$ and social capital ${ }^{9}$ - have been associated with teenage birth rates. Their effects, however, were modest and together leave much of the variation unexplained. Only one previous study has examined the influence of state spending on teenage pregnancy. This study showed that lower social welfare benefits are associated with higher teenage birth rates. ${ }^{8}$ Previous research has not examined the association between statelevel spending on a broader set of social services (eg, education, housing, income and nutritional support) and teenage birth rates.

Social service and public health spending might affect teenage birth rates in several ways. First, spending on education may result in better quality school systems, greater student engagement and thus increased economic opportunities. ${ }^{10} 11$ Additionally, more afterschool and summer programming for youth might result in greater adult monitoring and mentoring. ${ }^{1213}$ These opportunities may translate to greater responsibilities among youth and less idle time. Second, social spending on housing may enhance residential stability, allowing families to be less fragmented and to build and capitalise on stronger social support and social capital. ${ }^{145}$ Third, spending on the environment or recreation and on public 
safety may provide additional safe spaces for community engagement. Fourth, social spending may provide lower income individuals with financial assistance, potentially improving psychosocial health and development, ${ }^{16}{ }^{17}$ thereby reducing adolescent engagement in sexual risk behaviours. ${ }^{18} 19$ Last, spending on transportation services and community healthcare programmes may result in less infrastructure inequality and thus improved access to healthcare and family planning services. ${ }^{20}$ This hypothesis aligns well with previous research suggesting that the decrease in teenage birth rates since the early 1990s has been partly attributed to reduced rates of sexual activity and increased use of contraception. ${ }^{821}$

Accordingly, we sought to examine whether states with higher social service spending have lower rates of teenage births across USA. Because such spending supports a variety of services that may mitigate an individual's risk of birth as a teenager, we hypothesised that states that spend more in areas such as income support, housing, education and nutritional assistance will have lower teenage birth rates. As no single database collects these contextual factors simultaneously, we combined a number of relevant databases. We used the most recent healthcare spending data from the National Health Expenditures Data (based on Centers for Medicare \& Medicaid data) and public health and social service spending data from the US Census Bureau for years 2005 through 2009. We used teenage birth rates from the Kaiser Family Foundation. This state-level analysis may provide insight into the variation in teenage birth rates across states and inform efforts by policy makers, healthcare providers and researchers to leverage both public health and social service spending to support a continued decline in teenage birth rates.

\section{METHODS}

\section{Study design}

We conducted an ecological study by constructing a dataset that included teenage birth rates and spending on social and public health services among the 50 states in USA. Spending data were limited to years 2005 through 2009, the most recent 5 -year period $(n=250)$ for which consistent data were available. Because the study uses publicly available, deidentified data, it was deemed exempt from review by the Institutional Review Board at Yale University School of Medicine.

\section{Measures}

Dependent variable

Our outcome was teenage birth rates per 1000 women between 15 and 19 years of age. These data were abstracted from the Kaiser Family Foundation at http://kff.org/ other/state-indicator/teen-birth-rate-per-1000/ for each state for the years 2007 through 2011 to investigate 2-year lagged effects.

\section{Independent variable}

We calculated the total social service and public health spending per population of individuals living below the federal poverty level, as the target of social spending tends to be low-income people. Social services included primary, secondary and higher education; income supports (eg, cash assistance, general relief for low-income or needs-tests beneficiaries of public welfare programmes); transportation (eg, airports, waterways, vessels, public mass transit systems); environment (eg, sanitation and recreational programming, conservation of natural resources); public safety (eg, law enforcement and fire protection) and housing (eg, aid for public or private housing and community development). These data were obtained from the US Census Bureau Annual Survey of State and Local Government Finances (US Census Bureau, 2014), the Social Security Administration, Administration for Children and Families and the US Department of Agriculture. Public health spending included expenditures for public health department activities, such as disease surveillance, Special Supplemental Nutrition Program for Women, Infants, and Children (WIC), community healthcare programmes, regulation of air and water quality and animal control. These spending data were obtained from the US Census Bureau.

\section{Covariates}

Covariates were selected based on their associations with teenage birth rates in previous literature, ${ }^{4578}$ and included several demographic and economic factors for each state. We gathered data from the US Census Bureau on the percent of the population under 18 years old, per cent female, per cent non-Hispanic White, per cent non-Hispanic Black, per cent Hispanic, per cent of adults aged 25 years or older with a high school diploma, per cent of population living in urban area and geographical region. We gathered data on unemployment rates from the US Department of Labor and the per cent of children living in single-parent household from National KIDS COUNT (http://datacenter.kidscount.org). State-level gross domestic product (GDP) per capita was obtained from the US Department of Commerce and Bureau of Economic Analysis, and Medicaid expenditure data were extracted from the National Health Expenditure Account data files maintained by Centers for Medicare and Medicaid Services.

\section{Statistical analysis}

We first generated means and SD by state to describe variation across states for the year 2009 . We then plotted the 2009 spending rate against the 2011 teenage birth rate to visualise this association; based on this plot, we hypothesised the existence of both linear and quadratic effects of spending. We then constructed an unadjusted marginal model using repeated measures to test the linear and quadratic effects of spending on teenage birth rates. The model specified a year fixed effect and took into account the non-independence of observations for each state across years by specifying repeated years within states, allowing for correlated residual error terms. We then 
extended this model by including covariates to adjust for potential confounders. All models used 2-year lagged spending rates in order to account for proposed time lag between effect of social spending and a subsequent birth. We also tested whether state-level GDP moderates associations between spending and teenage birth by including an interaction term between GDP (high vs low) and spending. Spending rate was centred at its mean to reduce correlation between variables for all models. There were no missing data.

We explored two potential modifications to our final model. First, we gathered data on the Gini index of income inequality from the American Community Survey (ACS); however, this variable was only available for the years 2006-2009. We also calculated abortion rates per female population ages 15-19 in each state by first abstracting the number of abortions reported by state from the ACS and then dividing this number by state-level population estimates from the US Census Bureau for the years 2005 through 2009. These data, however, were unavailable for several states across the years. We explored their effects by including these variables in our final model among their respective subsets of available data. All analyses were performed with SPSS V.21.0 (Chicago, Illinois, USA).

\section{RESULTS}

\section{State descriptive statistics}

Table 1 displays means and SD of state-level teenage birth rates, social service and public health spending per individual living in poverty and covariates for the year 2009. On average, the teenage birth rate was 37.7 per 1000 female population ages 15-19 in 2009; this rate dropped to 31.3 births per 1000 population ages 15-19 in 2011 . On average, the social spending rate was approximately US $\$ 59960$ per individual living in poverty.

\section{Association between teenage birth rates and spending, using lagged effects}

The scatter plot of the association between teenage birth in 2011 and spending rates in 2009 is shown in figure 1. The unadjusted model across all years suggested that including both linear and quadratic effects of spending fit the data better than including only a linear effect of spending. Results revealed significant effects of spending. Higher spending rates were associated with lower rates of teenage birth; however, these effects diminished slightly with increases in spending (linear effect: $\mathrm{B}=-0.61 ; 95 \%$ CI -0.66 to $-0.56 ; \mathrm{p}<0.001$ and quadratic effect: $\mathrm{B}=0.01 ; 95 \%$ CI 0.01 to $0.01 ; \mathrm{p}<0.001)$.

Results of the adjusted model are shown in table 2. Accounting for all covariates attenuated the unadjusted associations in the overall sample. The marginal model suggests that there exists both linear and quadratic effects, such that every US\$1000 increase in the social spending rate was associated with decreases in the teenage birth rates overall, with effects slightly diminishing with increasing social spending (linear effect: $\mathrm{B}=-0.20 ; 95 \%$

\begin{tabular}{|c|c|}
\hline & Mean (SD) \\
\hline$\%$ Under 18 & $24.0(1.88)$ \\
\hline$\%$ Female & $50.7(0.73)$ \\
\hline \% Non-Hispanic White & $80.9(12.38)$ \\
\hline \% Non-Hispanic Black & $10.6(9.62)$ \\
\hline \% Hispanic & $10.4(9.91)$ \\
\hline \% Children living in single-parent home & $32.6(5.25)$ \\
\hline \% Individuals with a high school diploma & $86.9(3.41)$ \\
\hline Unemployment rate & $8.4(1.96)$ \\
\hline$\%$ Individuals living below poverty & $13.8(3.07)$ \\
\hline$\%$ Urban & $71.7(14.90)$ \\
\hline $\log (G D P / c a p i t a)$ & $2.5(0.17)$ \\
\hline Medicaid (US\$100 000) & $68.8(88.38)$ \\
\hline \multicolumn{2}{|l|}{ Region (n (\%)) } \\
\hline New England & $30(12.0)$ \\
\hline Mideast & $25(10.0)$ \\
\hline Great Lakes & $25(10.0)$ \\
\hline Plains & $35(14.0)$ \\
\hline Southeast & $60(24.0)$ \\
\hline Southwest & $20(8.0)$ \\
\hline Rocky Mountain & $25(10.0)$ \\
\hline Far West & $30(12.0)$ \\
\hline Social spending* (US\$1000) & $60.0(20.70)$ \\
\hline Teenage birth rate in $2009^{\dagger}$ & $37.7(11.47)$ \\
\hline Teenage birth rate in $2011^{\dagger}$ & $31.3(9.64)$ \\
\hline
\end{tabular}

*Social spending=(Social service spending+public health spending)/individuals living in poverty.

†Per 1000 population ages 15-19.

GDP, gross domestic product.

CI -0.31 to $-0.08 ; \mathrm{p}<0.001$ and quadratic effect: $\mathrm{B}=0.003$; $95 \%$ CI 0.002 to $0.005 ; \mathrm{p}<0.001)$. Estimates were slightly higher in magnitude and remained statistically significant when excluding outlying states (Arkansas, Wyoming). Subsequent analyses demonstrated consistent effects on teenage birth rates when using spending variables lagged by 1 year (linear effect: $\mathrm{B}=-0.23 ; 95 \%$ CI -0.35 to -0.12 ; $\mathrm{p}<0.001$ and quadratic effect: $\mathrm{B}=0.004 ; 95 \%$ CI 0.002 to $0.005 ; \mathrm{p}<0.001$ ) and by 3 years (linear effect: $\mathrm{B}=-0.16$; $95 \%$ CI -0.28 to $-0.05 ; \mathrm{p}<0.001$ and quadratic effect: $\mathrm{B}=0.003 ; 95 \%$ CI 0.002 to 0.005 ; $\mathrm{p}<0.001$ ). Additionally, we found no evidence that state-level GDP moderates associations between spending and teenage birth rates, as neither of the interaction terms testing this association was statistically significant $(\mathrm{p}>0.3)$.

Inclusion of the Gini index of income inequality did not meaningfully change the parameter estimates for the linear or quadratic effect of the social spending rate (linear effect: $\mathrm{B}=-0.18 ; 95 \%$ CI -0.30 to -0.06 ; $\mathrm{p}=0.004$ and quadratic effect: $\mathrm{B}=0.003 ; 95 \%$ CI 0.002 to $0.005 ; \mathrm{p}<0.001)$ and was not statistically significant in the 


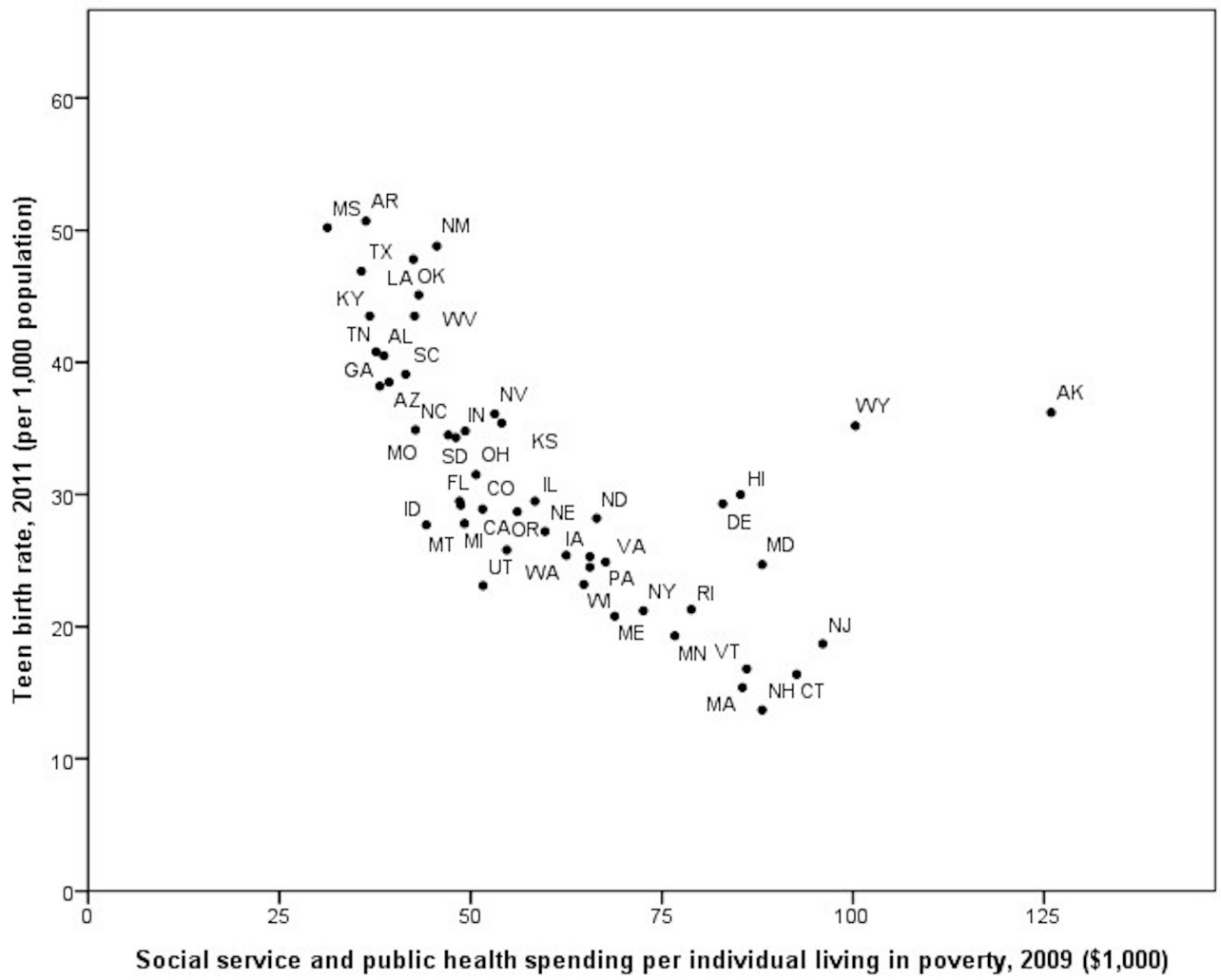

Figure 1 Association between 2009 social spending rates and 2011 teenage birth rates in USA.

model. When teenage abortion rates were included in the final multivariable model $(\mathrm{n}=223)$, they were also not significantly associated with teenage birth rates $(\mathrm{B}=0.09$; $95 \%$ CI -0.04 to $0.22 ; p=0.183$ ); however, the inclusion of teenage abortion rates strengthened the associations between spending and teenage birth rates (linear effect: $\mathrm{B}=-0.34 ; 95 \%$ CI -0.45 to $-0.22 ; \mathrm{p}<0.001$ and quadratic effect: $\mathrm{B}=0.005 ; 95 \%$ CI 0.003 to $0.006 ; \mathrm{p}<0.001$ ). Abortion rates, thus, appeared to be a negative confounder of this relationship between social spending and teenage birth rates.

\section{DISCUSSION}

Our results indicate that between 2005 and 2009, states with higher spending on social services had lower rates of teenage births, even when accounting for commonly identified risk factors. These covariates explained part of the magnitude of the effect seen in our unadjusted analysis, but the reduced effect remained statistically significant in our adjusted models. Every US $\$ 1000$ increase in the social spending rate was associated with a decrease of approximately $1 \%(0.64 \%-1.44 \%)$ of the average teen birth rate in 2011 (31.3 per 1000 females $15-19$ years of age). ${ }^{2}$ These results, which focus on multiple spending components, extend previous findings that focus on public policies. ${ }^{8}$ Although we cannot establish causality with these observational data, the use of lagged effects and the robust and consistent associations are noteworthy.

Our findings should be interpreted in light of some limitations. First, the analysis is a state-level analysis and should not be used to make inference about causal relationships at an individual level. Nevertheless, as the goal was to provide exploratory data to policy makers and practitioners about state-level spending choices, the patterns of association are notable. Second, our analysis was limited to 5 years of data, and although we were able to model the effect of previous spending on subsequent teenage birth rates, we were prevented from looking at longer-term effects. Additionally, this association was found using data from the years 2005-2009 and thus, may not be generalisable to current patterns in teenage birth rates. Our analysis was also limited by data availability. For instance, we had limited access to abortion rates for females ages 15-19 and the Gini index. Furthermore, we were unable to ascertain birth rates per state by poverty level, which may be particularly important, because our spending measure is per person living in poverty. These data would have allowed us to determine whether or not the effects of spending were stronger among those living below the poverty line compared with those living above the poverty line. Despite this, we believe our findings add importantly to the literature on social determinants, which indicates that social determinants of health can affect whole communities rather than particular segments of communities. Last, we were unable to detect which social services were most strongly associated with teenage birth rates, as spending on different services were highly correlated in these observational data. Although understanding the effects of specific programmes may be possible with controlled interventional studies, our 


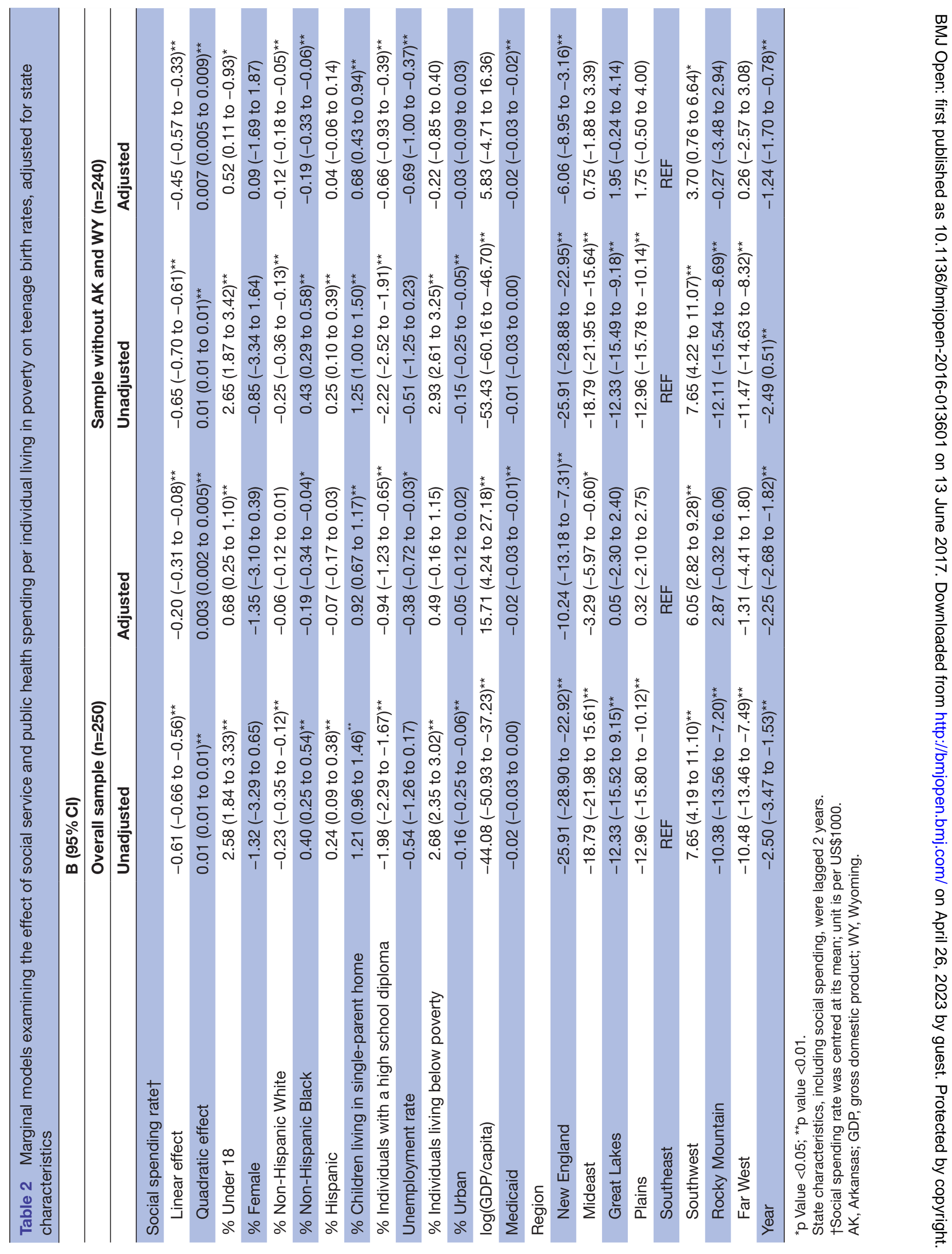


observational findings recognise that many of these programmes are interlinked, and separating their effects may not be realistic in practice.

In summary, greater investment in social services appears to lower teenage birth rates across states in USA. Despite the limitations of this analysis, results suggest a contextual and multilevel approach may be effective for continuing the decline in teenage birth rates.

Correction notice This paper has been amended since it was published Online First. Owing to a scripting error, some of the publisher names in the references were replaced with 'BMJ Publishing Group'. This only affected the full text version, not the PDF. We have since corrected these errors and the correct publishers have been inserted into the references.

Contributors HLS, MC, and EB conceptualised the design of the study and gathered the data. HLS and MC conducted the analyses, and HLS wrote the first draft. All authors contributed to the interpretation of results, revising the paper and approve the final version for submission.

Funding This work was funded by grants from the Robert Wood Johnson Foundation (grant no 71531) and Blue Cross Blue Shield of Massachusetts Foundation, Inc.

Competing interests None declared.

Provenance and peer review Not commissioned; externally peer reviewed.

Data sharing statement All data used in this analysis are publicly available; no unpublished data were used.

Open Access This is an Open Access article distributed in accordance with the Creative Commons Attribution Non Commercial (CC BY-NC 4.0) license, which permits others to distribute, remix, adapt, build upon this work non-commercially, and license their derivative works on different terms, provided the original work is properly cited and the use is non-commercial. See: http://creativecommons.org/ licenses/by-nc/4.0/

(c) Article author(s) (or their employer(s) unless otherwise stated in the text of the article) 2017. All rights reserved. No commercial use is permitted unless otherwise expressly granted.

\section{REFERENCES}

1. Sedgh G, Finer LB, Bankole A, et al. Adolescent pregnancy, birth, and abortion rates across countries: levels and recent trends. $J$ Adolesc Health 2015;56:223-30.

2. Martin J, Hamilton BE, Osterman MJK, et al. Births: final data for 2013. National Vital Statistics Reports 2015;64.
3. Taylor JL. Midlife impacts of adolescent parenthood. J Fam Issues 2009;30:484-510.

4. Meade CS, Kershaw TS, Ickovics JR. The intergenerational cycle of teenage motherhood: an ecological approach. Health Psychol 2008;27:419-29.

5. Sipsma H, Biello KB, Cole-Lewis $\mathrm{H}$, et al. Like father, like son: the intergenerational cycle of adolescent fatherhood. Am J Public Health 2010;100:517-24.

6. Kimball R, Wissner M. Religion, poverty, and politics: their impact on women's reproductive health outcomes. Public Health Nurs 2015;32:598-612.

7. Gold R, Kennedy B, Connell F, et al. Teen births, income inequality, and social capital: developing an understanding of the causal pathway. Health Place 2002;8:77-83.

8. Kearney MS, Levine PB. Investigating recent trends in the U.S. teen birth rate. J Health Econ 2015;41:15-29.

9. Crosby RA, Holtgrave DR. The protective value of social capital against teen pregnancy: a state-level analysis. J Adolesc Health 2006;38:556-9.

10. Wenglinsky H. Finance Equalization and Within-School Equity: the relationship between Education spending and the Social distribution of Achievement. Educ Eval Policy Anal 1998;20:269-83.

11. Condron DJ, Roscigno VJ. Disparities within: unequal spending and Achievement in an Urban School District. Sociol Educ 2003;76:18-36.

12. Dworkin JB, Larson R, Hansen D. Adolescents' accounts of growth experiences in youth activities. J Youth Adolesc 2003;32:17-26.

13. Knifsend CA, Graham S. Too much of a good thing? How breadth of extracurricular participation relates to school-related affect and academic outcomes during adolescence. $J$ Youth Adolesc 2012;41:379-89.

14. Carpiano RM. Neighborhood social capital and adult health: an empirical test of a Bourdieu-based model. Health Place 2007;13:639-55.

15. Sampson RJ, Morenoff JD, Earls F. Beyond social capital: spatial dynamics of collective efficacy for children. Am Sociol Rev 1999;64:633-60.

16. McLaughlin KA, Green JG, Alegría M, et al. Food insecurity and mental disorders in a national sample of U.S. adolescents. J Am Acad Child Adolesc Psychiatry 2012;51:1293-303.

17. Alaimo K, Olson CM, Frongillo EA. Food insufficiency and american school-aged children's cognitive, academic, and psychosocial development. Pediatrics 2001;108:44-53.

18. Brown LK, Tolou-Shams M, Lescano C, et al. Depressive symptoms as a predictor of sexual risk among african american adolescents and young adults. J Adolesc Health 2006;39(3):444.e1-444.e8.

19. Lehrer JA, Shrier LA, Gortmaker S, et al. Depressive symptoms as a longitudinal predictor of sexual risk behaviors among US middle and high school students. Pediatrics 2006;118:189-200.

20. Viner RM, Ozer EM, Denny S, et al. Adolescence and the social determinants of health. The Lancet 2012;379:1641-52.

21. Kearney M, Levine P. Why is the teen birth rate in the United States so high and why does it matter? Cambridge, MA: National Bureau of Economic Research, 2012. 